International Journal of Instruction e-ISSN: 1308-1470 • www.e-iji.net

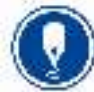

Article submission code: 20200628073952
Received: 28/06/2020

Revision: 26/01/2021
July $2021 \bullet$ Vol.14, No.3

p-ISSN: 1694-609X

pp. $827-846$

Accepted: 18/02/2021

OnlineFirst: 19/06/2021

\title{
The Effects of Teaching Methodologies on Students' Attitude and Motivation: A Meta-Analysis
}

\section{Shalom Grace C. Sugano}

Asst. Prof., II, College of Education, Visayas State University, VSU, Visca, Baybay City, Leyte, 6521, Philippines, shalomgrace.sugano@vsu.edu.ph

\section{Leo A. Mamolo}

Asst. Prof., I, College of Education, Visayas State University, VSU, Visca, Baybay City, Leyte, 6521, Philippines, leo.mamolo@vsu.edu.ph

Literature shows that there is very little research focusing on the analysis of the effectiveness of teaching methodologies on the affective domain of the students. Effective instruction should be designed to cater to the individualities of learners that holistically develop not only the cognitive but also the affective domain. This requires teaching methods that have an integrative structure that focuses on the effective learning of the students. This study emphasizes the effect on students' attitudes and motivation upon the use of different teaching methods through the meta-analysis technique. This method aims to combine chemistry education research findings that were conducted in the Philippines from 2015 to 2016. Identified teaching methods cast into treatment categories that act as the independent variable. Research findings of 14 studies that meet the inclusion criteria for meta-analysis are included in the analysis to determine the size of the mean effect of different treatment categories on attitude and motivation as compared to traditional teaching. Findings showed that a significant positive effect (Cohen's $\mathrm{d}=0.379$ ) was observed upon the use of teaching methods on attitude while a non-significant effect was observed on motivation. The study revealed that cooperative learning showed a significant effect than the traditional teaching method in promoting positive attitude and motivation/interest of the students towards learning chemistry. The results suggest that more empirical studies have to be pursued to give teachers a concrete understanding of the different ways of developing students' affective domain.

Keywords: affective domain, effect size, chemistry education, treatment categories, teaching methodologies

\section{INTRODUCTION}

Any teaching method aims to develop students holistically. These methods intend to improve students' academic performance, positive attitudes towards the subject matter,

Citation: Sugano, S. G. C., \& Mamolo, L. A. (2021). The effects of teaching methodologies on students' attitude and motivation: A meta-analysis. International Journal of Instruction, 14(3), 827846. https://doi.org/10.29333/iji.2021.14348a 
and mastery of skills stipulated in the curriculum. The teaching method presents the general management strategies, principles, and pedagogies applied in the teachinglearning process (Muhammad, 2019). It is a detailed manner of presenting the subject matter. It denotes the kind of teaching strategy and techniques used in the classroom (Gill \& Kusum, 2016). As emphasized by Bloom (1956), instruction structured in such a way that the cognitive, affective, and psychomotor properties of learners are covered. That is why; all these instructional activities must be well structured and employed concerning the development of the different domains (Demirel, 1999; Gömleksiz, 2003). Furthermore, as emphasized by Mamolo (2019), teachers may find ways to consider utilizing other teaching strategies to deal with the students in a more engaging manner.

In the past ten years, nine teaching methodologies have been executed and studied in chemistry instruction (Sugano, Nabua, Barquilla, Buan, \& Inutan, 2019). These include; combination learning, cooperative learning, inquiry-based learning, individualized instruction, manipulative and multiple representations, multicultural education, problembased learning, project-based learning, and technology-based instruction. Sugano and Nabua (2020) found out that the usage of these nine different teaching methods displayed a significant impact on academic performance. The results answer to the concerns of educational researchers on how effective the established teaching methods to the learning of the students (Ganyaupfu, 2013). The strategies enumerated were known to improve students cognitively or the mental skills of the learners developed (Bloom, 1956). The other domains of learning to account for students' development must also consider (Demirel, 1999; Gömleksiz, 2003). Just like in problem-based learning that integrates the cognitive, affective, and psychomotor learning domains in the teaching-learning process (cited in Demirel \& Dagyar, 2016) and the positive impact of the use of multimedia on students' achievement and attitudes (Aloraini, 2012).

The affective domain includes areas such as attitudes, concerns, interests, motivations, and personalities of students (Bloom, 1956). Attitude refers to a way of behavior, thinking, feelings, or response to certain things, people, places, events, or ideas (Papanastasiou \& Zembylas, 2002) that indirectly exist in an individual's life. It stems from someone's observable behaviors (Ilgaz, 2006). Attitude is widely researched and is considered one of the constructs of the affective domain for over 40 years. In the teaching-learning process, students should adopt a positive attitude toward the subject matter because it is an essential feature of the affective domain (Demirel \& Dağyar, 2016). Nasr (2011) emphasized that student's attitude is one of the primary factors in learning science. Thus, possessing positive attitudes in students can promote interest and motivation in science education courses. Attitude may predict future preferences, an association between attitude and future behaviors, especially if there is a direct interaction between the students and the attitude objects (Glasman and Albarracín, 2006).

Many kinds of literature explore widely on the possible factors influencing attitude toward learning science. Can (2012) cited primary reasons why attitude is in demand for investigation and further studies. It concerns on its feasible power to predict future behaviors like the subject-matter and career preferences of the students, and the 
significant correlation between attitude and academic achievement. Indeed, several studies found and cited that science attitudes positively correlates with science achievement (Akcay, Durmaz, Tuysuz, \& Feyzioglu, 2006; Nasr, 2011; Can, 2012). In Bloom's theory of school learning, $25 \%$ of the variance in school achievement could attribute to the student's school environment, self-efficacy, and attitudes toward the subject. Adesoji (2008) reported that teaching methods are one of the factors that relate to students' attitudes in science. If students develop higher cognitive thinking skills through inquiry-based learning (Rybbczynsk \& Schussler, 2012), computer-based learning (Akcay et al., 2006), and problem-solving strategies (Adesoji, 2008; Bogar, Kalender \& Sarikay, 2012), their attitudes toward the subject matter can change positively. Thus, studies on the effectiveness of different teaching methodologies on chemistry education on attitudes are an impactful contribution to the body of literature.

Motivation is another area of the affective domain. It is a drive or control of a person that strengthens, guides, enhances or maintains their behavior (Tohidi \& Jabbari, 2012). It is also an internal state or condition described as a need, desire, or want that serves to activate behavior and give it direction (Schunk, Meece \& Pintrich, 2008). Stirling (2013) highlighted that motivation is an interesting topic of the researchers in different fields, including business, human development, education, psychology, and sociology. In the teaching-learning process, motivation is a vital element. It is a pre-requisite for students to be engaged in the learning process (Saeed \& Zyngier, 2012). Several studies already investigated the effects of teaching methods on student's motivation. Cudney and Ezzell (2017) studied that the use of various teaching strategies creates a positive impact on the student's learning and that they promote a change in student's motivation. Moreover, several kinds of the research reported the positive effect of the utilization of different teaching methods/strategies like blended learning (Oweis, 2018), technologybased learning (Gabrielle, 2003; Wang \& Keeves, 2007; Francis, 2017), cooperative learning (Hancock, 2010), inquiry-based learning (Bayram, Oskay, Erdem, Ozgur \& Sen, 2013; Cheng, Yang, Chang \& Kuo, 2016), project-based learning (Chiang \& Lee, 2016), and use of the interactive mobile application (Mamolo, 2019a) towards students' motivation. However, an insignificant effect towards motivation obtained upon the use of constructivist learning; inquiry-based learning (Calikskan, 2004; Johnson \& Cuevas, 2016; Dindar, 2016), and problem-based learning (Wijnia, Loyens \& Derons, 2011; Argaw, Haile, Ayalew \& Kuma, 2016). Despite these data, there is no available information that synthesizes findings of independent studies to examine the efficacy of these teaching methods used in chemistry classrooms to students' motivation and attitude.

Thus, we aim to synthesize and meta-analyze chemistry education studies completed from 2005 to 2016. A meta-analysis is a quantitative and systematic statistical technique design to combine and synthesize findings of independent research studies. It is a statistical analysis of an extensive collection of analyses from different studies to integrate the conclusions (Glass, 1976). The approach used combines data and summarizes findings of individual studies to determine the effect of a similar treatment approach to a similar group of respondents (Israel \& Richter, 2011). 


\section{Aim of the Study:}

The primary purpose of our study is to examine the effectiveness of teaching methods on student's affective domain (attitude and motivation) in secondary chemistry. With this, it aims to investigate the following research questions:

1. What is the overall effect size of the studies included in the meta-analysis upon the utilization of different treatment categories towards attitude and motivation?

2. What is the treatment category that has the largest effect size towards attitude and motivation?

\section{METHOD}

\section{Research Design}

We utilized an Ex Post Facto research design in this study as it involved a meta-analysis of chemistry education research findings (Figure 1). This method aims to examine and combine all pertinent studies, both published and unpublished, so that a weighted mean effect size would be derived. Meta-analysis aims to combine statistical analysis of the quantitative findings of the independent and related studies and results of the studies coherently and consistently (Cohen, 1988). We employed the quantitative approach to evaluate the impact of teaching methods on attitude and motivation in chemistry instruction. The meta-analysis technique quantitatively synthesized the studies of impact to produce a clear picture of the relationship among variables. We converted the gathered findings of investigations into the standard measurement unit called effect size. 


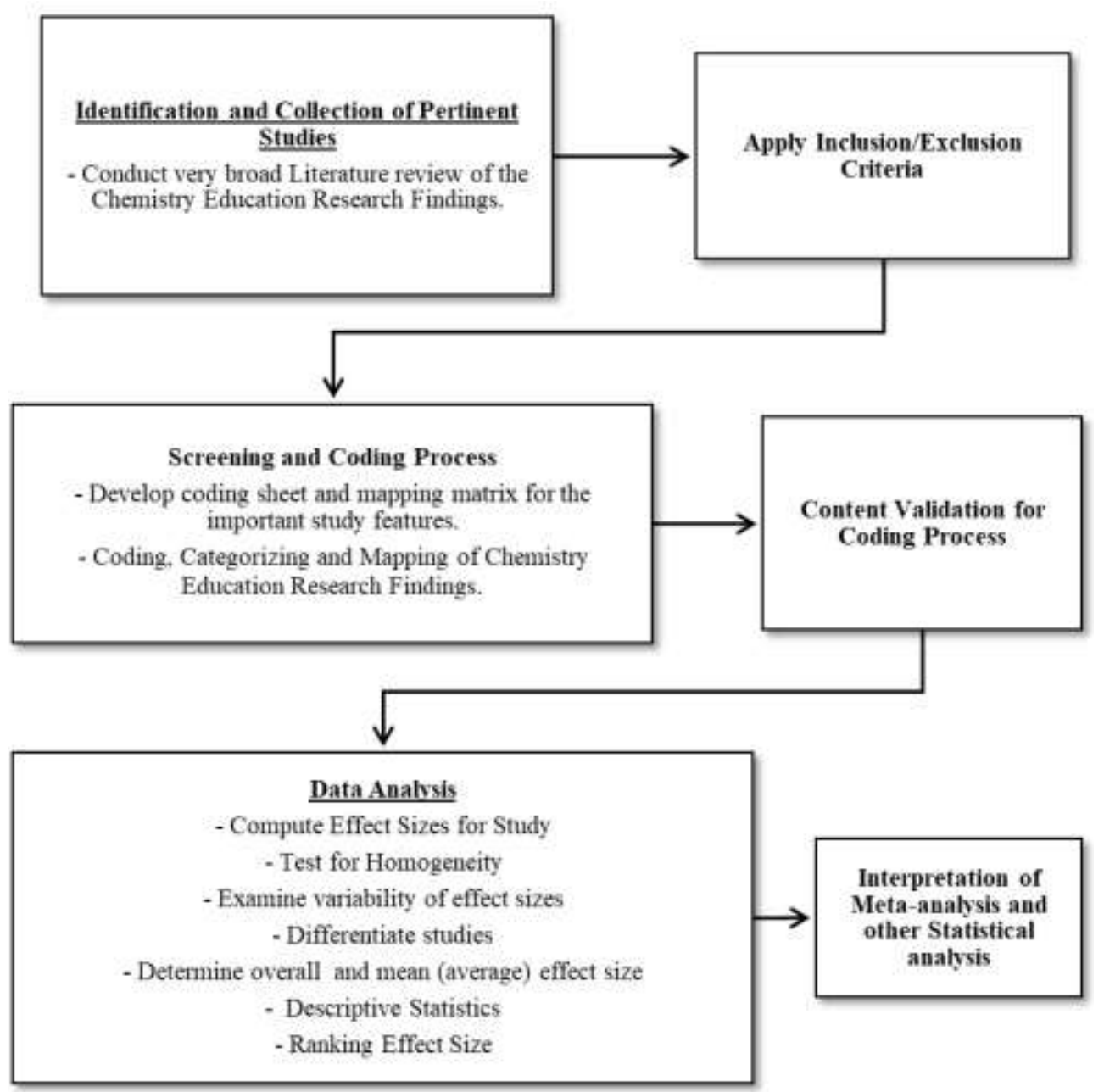

Figure 1

Overview of the research design

\section{Data Sources}

We gathered a total of 33 empirical studies from theses, dissertations, conference proceedings, and journal articles of both published and unpublished in chemistry education. Based on the framework of the established inclusion criteria, fourteen studies with three published and eleven unpublished qualified in the meta-analysis. We systematically searched and collected studies from both private and public universities in the Philippines. Also, the qualified empirical studies in chemistry education were reviewed and coded based on the characteristics or features. 


\section{Research Instruments}

In this study, we used the following instruments in conducting the meta-analysis. First, we utilized the study qualifying forms in the pre-screening process to identify the empirical researches that included in the analysis based on the established criteria for inclusion. Second, we modified and used coding forms in the coding process of the meta-analysis to convert the gathered information to numerical data. Third, we developed the data layout matrices, to sum up the abstracted data from the coding form. These matrices also facilitate the systematic evaluation of each study's findings included in the meta-analysis. Lastly, we developed mapping matrices to present and group the different variables (independent and dependent). Also, we compared the dataset of each treatment variable. We ranked the weighted effect size to determine the treatment categories using the matrices.

\section{Data Gathering Procedures}

Research studies involving attitude and motivation as influenced by the use of different teaching methods applied in secondary chemistry instruction were collected. We conducted a logical search procedure and literature review to identify and gather the potential and eligible chemistry education studies from the published and unpublished graduate theses and dissertations. Also, we consulted an electronic database through computerized search in the following; ERIC (Education Resource Information Center), Proquest, and Google Scholar. Online searches and reviews in journals of educational organizations for local and foreign executed.

We conducted surface level screening in each of the gathered chemistry education research. We examined the full text in the case where the essential characteristics were not evident in the title and abstract. A study that did not meet the given inclusion criteria eliminated in the meta-review. All studies included in the meta-analysis passed in the established inclusion criteria. The following criteria used to assess the eligibility of studies:

1) The study focused on the affective domain (attitude and motivation) resulting from the use of different teaching methods.

2) It was conducted and completed in the Philippines between 2005 and 2016.

3) It involved in secondary chemistry instruction.

4) The study used either an experimental or quasi-experimental design.

5) The study reported statistical information like mean, degree of freedom, sample size, $t, f$ and $p$ values, standard deviations, and ANOVA tables sufficient to compute effect size (ES).

A total of 14 studies that fit the inclusion criteria were identified after the conducted extensive literature review. The meta-analysis studied the relationships between the dependent variables and the potentially contributing independent variables (Cavanaugh, 1998). We cast the specified different teaching methods into treatment categories to 
explore the heterogeneity of effect sizes among the qualified research findings. There were nine (9) identified treatment categories that served as the independent variable in this study. On the other hand, the affective domain consisting of attitude and motivation were the dependent variable of the meta-analytic review.

\section{Coding Process}

Three (3) Ph.D. level professionals in science education conducted the coding process in all studies qualified in the study. They carried out the coding process individually using a coding scheme with the study features. In this study, we developed the coding sheets to delineate each study's features based on the data extracted. Hence, we gave careful attention to eligible studies, as these served as the framework for analysis. Qualitative and quantitative data coded using the coding sheet to permit the comparison of findings across studies. The coders guided with a detailed quantitative description of the different characteristics included in the case of the study. The data extracted from each study were coded based on the study features identified in this meta-analysis.

Also, treatment categories were used in the study as a comparison of the efficacy of different teaching methods on student attitude and motivation. A separate coding process was solely conducted for the classification of teaching methods. Teaching method categories were named and defined based on the review of literature on chemistry teaching methods, and after the thorough reading of the studies included in the meta-analysis, this paved way in generating and establishing the set of categories applied in this study. Within this process, the decision for classification into treatment categories is based on the definition and purpose of the teaching method, as described in the research analyzed.

\section{Content Validation}

Content validation was performed on the instruments used in this meta-analysis. Three experts on science education, statistics, and assessment and evaluation conducted the content validation process. Moreover, the research instruments were examined by the experts individually. The corrections and suggestions made were collected and integrated for the refinement of the instruments.

\section{Reliability Test}

We performed reliability tests on the conducted study coding and mapping processes and used percent agreement. This measure presents the average percentage agreement on coding samples between independent coders. Three (3) studies were randomly chosen and were used to compute the percent agreement. The sample studies were also coded and were then compared item by item. The researchers with two science educators (a Ph.D. and a master's degree holder) with a strong background in statistics reviewed and coded all the qualified studies individually. The degree of agreement between coders was $89.85 \%$ hence, guarantee the reliability of the study. The values obtained from $70 \%$ and above are considered acceptable and reliable (Ayaz \& Sekerci, 2015). Disagreeing items between the coders were re-examined and resolved through discussion and mutual decision. 


\section{Data Analysis}

We used a Microsoft Excel Spreadsheet to compile all coded studies, to collect and to organize the extracted data. We created an excel form to prompt for all needed features for each research and automatically save the information in a database from which analyses would conduct. The data were analyzed using the Comprehensive Metaanalysis Program/Software.

We performed the following statistical computation in the meta-analysis. We computed the effect sizes for each study, differentiated and determined the weighted mean effect sizes, and tested the homogeneity of data. Meta-analysis is a statistical analysis that integrates results from two or more studies providing a single numerical value of the overall treatment effect. To interpret a meta-analysis, researchers must understand the different statistical concepts and processes, including effect size, heterogeneity, effect model, and forest plot used in the study. We presented confidence intervals in the metaanalysis results, and this includes the upper and lower limits that capture the range of values around the real but unknown population value. The $95 \%$ CI used in this study, and it corresponds with the typical 5\% significance level used in hypothesis tests. The number of studies, percentage, mean effect size, and the standard deviation reported as a standard error in this study were determined and utilized. These data presented the descriptive statistical findings of the study variables of each qualified research.

A final way to interpret an effect size is to give a value. Interpreting the results of a meta-analysis requires the understating of the established standards that would allow for meaningful interpretation of effect sizes (Shachar \& Neumann, 2010). Cohen's (1988) guideline served as the basis to evaluate the significance of effect size. It also determines whether a significant standard deviation of at least $0.25-0.50$ improvement can be achieved or expected from the use of teaching methodologies. In the interpretation of effect sizes obtained from the results of meta-analysis, the categories used.

1. Standardized mean difference effect size (Cohen's d)

$0 \leq$ Effect size value $\leq 0.50$ - small

$0.51 \leq$ Effect size value $\leq 0.80$ - medium

$0.81 \leq$ Effect size value $\leq 1.00$ - large

$1.01 \leq$ Effect size values, strong, has an important effect

Forest plot is one of the most useful tools used in this meta-analysis. It provides a visual summary of the analysis and findings. It graphically represented estimates of the effect size and corresponding confidence intervals for each study. In this study it also presented the mean effect size and the corresponding overall confidence interval of all qualified studies. We also utilized forest plots to analyze the variation within and among studies visually. The forest plots presented include the numerical value of the treatment effect and the variability of each treatment category concerning the affective domain parameters. 


\section{FINDINGS}

\section{Frequency of Eligible Studies on Attitude and Motivation}

The meta-analysis results for the studies examining the effects of the treatment category concerning the student's attitude is presented in Table 1. A reflected in the table, a total of twelve $(n=12)$ research studies were reviewed and qualified in the meta-analysis upon the use of different teaching methods on student's attitudes in secondary chemistry.

Table 1

Frequency of eligible studies on attitude

\begin{tabular}{lll}
\hline Treatment Categories & Number of Studies & Percentage (\%) \\
\hline Cooperative Learning & 3 & 27.27 \\
\hline Individualized Instruction & 2 & 18.18 \\
\hline Project-based Learning & 2 & 18.18 \\
\hline Inquiry-based Learning & 1 & 9.09 \\
\hline Problem-based Learning & 1 & 9.09 \\
\hline Manipulative and Multiple Representations & 1 & 9.09 \\
\hline Technology-aided Instruction & 1 & 9.09 \\
\hline Multicultural Education & 1 & 9.09 \\
\hline Combination Learning & 0 & 0 \\
\hline Total Studies & $\mathbf{1 2}$ & 100 \\
\hline
\end{tabular}

In the study of Haas (2002), six teaching methodology types were used. In this metaanalysis, we expanded the area into nine (9) to include the recent trends in chemistry education and the introduction of multicultural education that is not widely available. The findings presented that out of the identified treatment categories, cooperative learning $(\mathrm{n}=3)$ ranks first on the type of method being studied on attitude. It was followed by project-based learning $(n=2)$ and individualized instruction $(n=2)$. A single study was qualified in the analysis based on the established criteria in the following methods; inquiry-based learning, manipulative and multiple representations, problem-based learning, multicultural education, and technology-aided instruction. No eligible study was reviewed on combination learning.

Table 2

Frequency of qualified studies on motivation

\begin{tabular}{lll}
\hline Treatment Categories & Number of Studies & Percentage (\%) \\
\hline Cooperative Learning & 1 & 50.00 \\
\hline Inquiry-based Learning & 1 & 50.00 \\
\hline Total Studies & $\mathbf{2}$ & 100 \\
\hline
\end{tabular}

In the efficacy of teaching methods on motivation, as shown in Table 2, it can be observed that only two (2) studies were qualified in the analysis. It is a critical issue to be resolved in a meta-analysis. We do not set restrictions in the gathering of data. 
Theoretically, there is no rule of thumb on the number of studies needed for metaanalysis. It can be conducted with "two studies" and even can be used with single research considering it has multiple results of the outcome and coupled with the appropriate statistical method (fixed or random) and accounting the variance of sample size (Valentine, 2010).

\section{Meta-analysis for All Studies}

Studies that qualified for meta-analysis are also grouped according to the study feature and the dependent variable, which refers to the affective domain that includes attitude and motivation. The random-effects model was applied in the meta-analysis, and it presented a heterogeneous effect size distribution. According to the model, the computed mean effect size for 12 studies is 0.379 , as shown in Table 3. At a confidence level of 0.05 , the $95 \%$ confidence limit was determined with a confidence interval limit superior of 0.586 and an interval limit inferior of 0.171 . The data imply that the null hypothesis of the population effect size is zero; thus, it can reject given Cohen's (1988) standard framework. It is revealed that the utilization of teaching methods has a positive impact on students' attitudes as compared to traditional teaching, but the effect is at a low level.

On the motivation domain, we found a weighted mean effect size of 0.453 , considered to be insignificant at the 0.05 confidence level. Confidence intervals of continuous measures that include zero surrounding the effect size and reach the negative limit represent non-significant results (Israel \& Richter, 2011). We inferred that the number of independent studies qualified in the analysis is one of the primary factors that affect the effect size of the outcome variable. As claimed by Kalaian \& Kasim (2014), the limited number of individual studies on the outcome variables leads to a weak statistical power of the statistical test.

Table 3

Meta-analysis for all studies

\begin{tabular}{llllll}
\hline Affective Domain & $\begin{array}{l}\text { Mean } \\
\text { ES }\end{array}$ & $\begin{array}{l}\text { Confidence Interval } \\
\text { (lower limit) }\end{array}$ & $\begin{array}{l}\text { Confidence Interval } \\
\text { (upper limit) }\end{array}$ & z value & p-value \\
\hline Attitude & 0.379 & 0.171 & 0.586 & 3.579 & $0.000^{*}$ \\
\hline Motivation & 0.443 & -0.311 & 1.217 & 1.163 & 0.000 \\
\hline p $<0.05$
\end{tabular}

\section{Effects of Teaching Methods on Attitude}

We examined the effects of different teaching methods on attitude and meta-analysis results, as shown in Table 4. Upon the use of the random-effects model, we observed significant weighted mean effect sizes in the following treatment categories; cooperative learning (Cohen's $\mathrm{d}=0.500$ ), project-based learning (Cohen's $\mathrm{d}=0.452$ ), and individualized instruction (Cohen's $d=0.388$ ). We interpreted that each of the obtained mean effect sizes corresponds to be small. It implies that these treatment categories can minimally affect student's attitudes as compared to traditional teaching. 
Table 4

A Meta-analysis of eligible studies on attitude

\begin{tabular}{lllllll}
\hline $\begin{array}{l}\text { Treatment } \\
\text { Categories }\end{array}$ & $\begin{array}{l}\mathrm{N} \\
\text { (Sample } \\
\text { Size) }\end{array}$ & $\begin{array}{l}\text { Mean Effect } \\
\text { Size } \\
\text { (Cohen's d) }\end{array}$ & $\begin{array}{l}\text { Confidence } \\
\text { Interval } \\
\text { (lower } \\
\text { limit) }\end{array}$ & $\begin{array}{l}\text { Confidence } \\
\text { Interval } \\
\text { (upper limit) }\end{array}$ & $\begin{array}{l}\text { z- } \\
\text { value }\end{array}$ & $\begin{array}{l}\text { p- } \\
\text { value }\end{array}$ \\
\hline $\begin{array}{l}\text { Cooperative } \\
\text { Learning }\end{array}$ & 191 & 0.500 & 0.311 & 0.690 & 5.18 & $0.000^{*}$ \\
\hline $\begin{array}{l}\text { Individualized } \\
\text { Instruction }\end{array}$ & 334 & 0.388 & 0.171 & 0.606 & 3.503 & $0.000^{*}$ \\
\hline $\begin{array}{l}\text { Project-based } \\
\text { Learning }\end{array}$ & 122 & 0.452 & 0.166 & 0.739 & 3.091 & $0.002^{*}$ \\
\hline *p<0.05 & & & & & &
\end{tabular}

Figure 2 graphically presents the distribution of the mean effect size across studies classified according to treatment categories for comparison. It shows that TC1 denoted as cooperative learning, has the largest mean effect size toward attitude among the three into treatment categories.

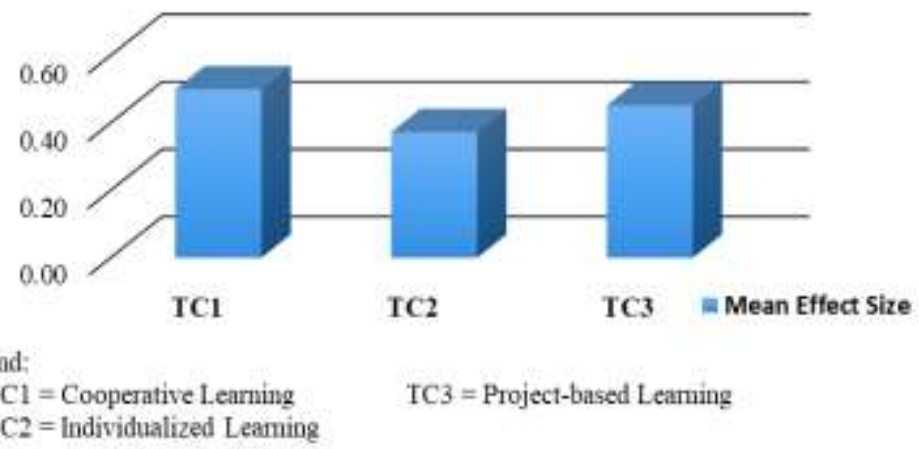

Figure 2

Graphical representation of mean effect sizes for treatment categories on attitude

The forest plot is presented in Figure 3 to give the full detail of the $95 \%$ confidence interval for each treatment category. It represents the estimates of the combined effect size along with the corresponding overall confidence interval of all qualified studies. In the same way, the effect size and the confidence interval of each study are presented on the forest plot. Teaching method categories reaching the negative continuous interval were considered to have no significant effect. 


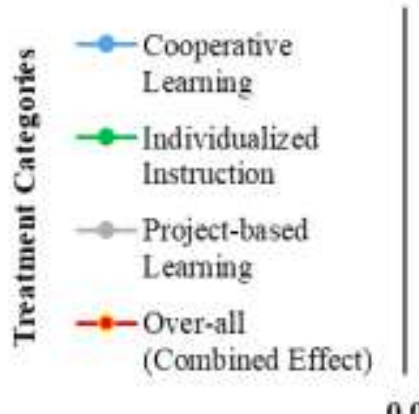

0.0
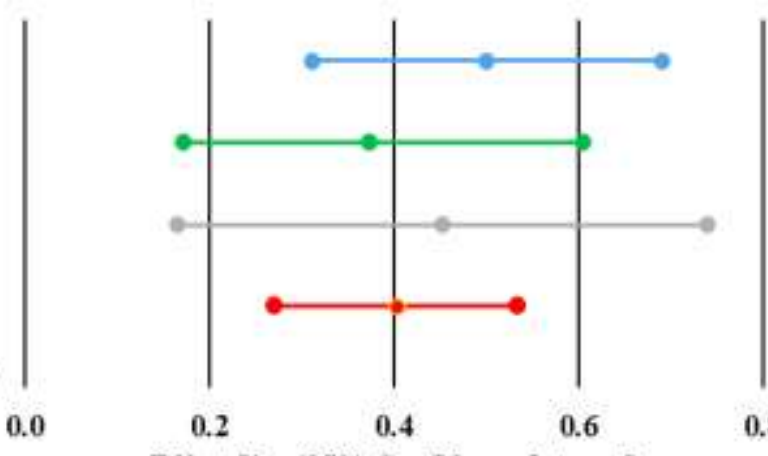

0.2

0.4

0.6

Effect Size (95\% Confidence Interval)

Figure 3

Forest plot of mean effect size for treatment categories on attitude

\section{Effects of Teaching Methods on Motivation}

According to the random-effects model, as presented in Table 5, the cooperative learning methods showed a significant large effect size (Cohen's $d=0.860$ ) on student's motivation. Based on the presented result, it can be implied that cooperative learning has a large positive effect on student motivation as compared to the use of traditional teaching. However, inquiry-based learning did not display any significant effect size (Cohen's $\mathrm{d}=0.080)$ on motivation.

Table 5

A Meta-analysis of eligible studies on motivation

\begin{tabular}{lllllll}
\hline Treatment Categories & $\begin{array}{l}\text { N (Sample } \\
\text { Size) }\end{array}$ & $\begin{array}{l}\text { Mean Effect } \\
\text { Size } \\
\text { (Cohen's d) }\end{array}$ & $\begin{array}{l}\text { Confidence } \\
\text { Interval } \\
\text { (lower } \\
\text { limit) }\end{array}$ & $\begin{array}{l}\text { Confidence } \\
\text { Interval } \\
\text { (upper } \\
\text { limit) }\end{array}$ & z value & p-value \\
\hline Cooperative Learning & 76 & 0.860 & 0.388 & 1.332 & 3.571 & $0.000^{*}$ \\
\hline $\begin{array}{l}\text { Inquiry-based } \\
\text { Learning }\end{array}$ & 64 & 0.080 & -0.265 & 0.425 & 0.454 & 0.650 \\
\hline *p<0.05 & & & & & &
\end{tabular}

The non-significant results were evident in the confidence interval, as shown in Figure 4 covers the lower and upper limit, where negative lower limit values were detected. The interval reaching zero is evident in the forest plot (Figure 4), which is an indication of being imprecise and uncertain. 


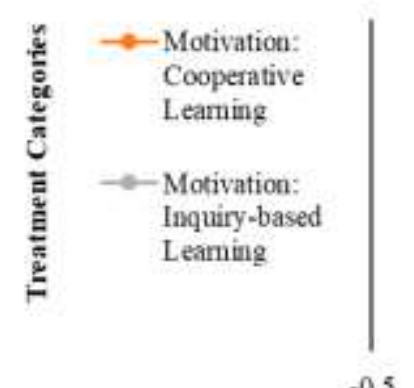

$-0.5$

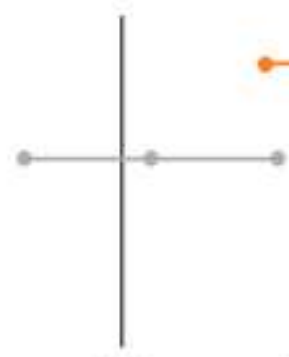

0.0

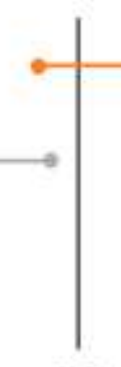

0.5

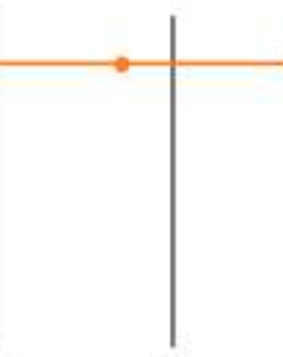

1.0

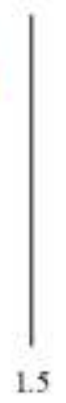

1.5

Figure 4

Forest plot of mean effect size for treatment categories on motivation

\section{DISCUSSION}

The primary purpose of this meta-analysis is to give a precise conclusion as a whole. It aims to assess the strength of the evidence present on a particular treatment in which individual studies were not able to cater due to some disagreements. As presented in Table 1, we accounted for only one study that was qualified in the following treatment categories. These are inquiry-based learning, manipulative and multiple representations, multicultural education, problem-based learning, and technology-aided instruction. Hence, each study has no multiple results presented. Valentine, Pigott, \& Rothstein (2010) emphasized that a single study with no multiple results is considered as "weak and "undersized," can even be ignored and is unreliable. Thus, the computed effect size in these treatment categories was considered to be inaccurate and inexplicable. The findings imply that more studies are still needed in these teaching methods to make reasonable and valid assumptions.

However, a single study was observed in this meta-analysis. Still, each of the treatment categories contains multiple findings presented in the study. Homogeneity tests were also conducted in each outcome variable to warrant the combination results. Each research finding was also weighted by generating the weighted effect size using the fixed-effect model. The minimal number of studies qualified in the meta-analysis on the motivation domain implied two possible reasons. It can be due to the novelty of the topic that calls for more empirical research in the future, or it is due to the lack of interest in the scientific community to investigate the issue.

The results revealed that there are limited available research studies conducted in the Philippines that investigate the efficacy of different teaching methods on student attitude and motivation in chemistry instruction. The results of the meta-analysis would help enlightened educators and researchers to analyze more on the effectiveness of different teaching methods in promoting the affective learning of the students. Several previous research (Schroeder, Scott, Tolson, \& Huang, 2007; Umer \& Siddiqui, 2013; Ayaz \& Sekerci, 2015; Sugano \& Nabua, 2020) have already proved the significant contribution 
of different teaching methods towards the academic performance. Still, very limited were accounted for the affective domains of the students. It was also emphasized that academic performance should not be the only main concern in educational research. Affective domains such as attitude, motivation, interest, and personality should also be an intensive focus. Moreover, this entails that teaching-learning applications used in instruction tend to neglect the affective domains such as attitude and motivation in comparison to the cognitive and psychomotor domains (Demirel \& Dagyar, 2016). Mamolo and Sugano (2020) emphasized the need to develop and implement appropriate educational interventions to promote the interest and motivation of students to improve the actual competence and academic performance in mathematics. The results of our meta-analysis support the idea that all domains of learning, including the mental (Sugano \& Nabua, 2020), affective (Demirel \& Dagyar, 2016), and psychological development of the students must be evident and be carried out in chemistry instruction.

Cooperative learning is viewed as a teaching-learning method where students work together on various tasks and to achieve a common goal. It is a useful tool to help develop a positive attitude toward learning (Johnsen, 2009). Several research studies affirmed that the cooperative learning method is better than the traditional method in terms of arousing a positive attitude (Ajaja \& Evarwoke, 2010; Capar \& Tarim, 2015). As cited by Haas (2005), the cooperative learning method possesses five elements. These elements are positive interdependence, effective face-to-face interaction, individual and group accountability, interpersonal in small-group skills, and group processing that enhance student learning. In a cooperative learning setting, learners are allowed to share and defend their knowledge, converse, and exchange ideas with peers. They actively engage in learning activities (Laal, Laal \& Kermanshahi, 2012). Students who are working together often enjoy the experience and can feel a sense of belongingness with their classmates. This kind of belief enables students to perceive that they are more successful academically (Johnsen, 2009). Through this, the learners will be challenged emotionally and socially as they listen to different perspectives, opinions, and views (Laal et al, 2012). Also, they are required to articulate and defend their ideas so that they can have the opportunity to re-evaluate and come up with solutions to problems (Johnsen, 2009; Laal et al., 2012). It is also emphasized that cooperation results in higher individual and group achievement, healthier relationships with peers, more excellent psychological health and self-esteem, and more metacognition (Johnson \& Johnson, 2014).

We found in this study that cooperative learning has a significant effect on promoting motivation towards learning chemistry than traditional teaching. This kind of teaching method is relevant in chemistry instruction because teachers allow students to work on a team on diverse tasks. As highlighted by Quinn (2006), students working in teams is encouraged to solve complex problems; hence, students must be taught and exposed to how to be active members of a team. The traditional teaching method's focus is to promote competition, to motivate the student, and to discourage student interaction. Through this, it tends to overlook strategies where cooperation can be evident and be used to inspire or motivate students in their everyday learning inside the classroom. Slavin (1984) presented that the positive motivational impact of peer support of learning 
is said to be one primary factor that makes cooperative learning a success. Quinn (2006) affirmed that peer tends to recognize that their rewards are based on the success of their teammates and are likely to provide support for each other's learning. Moreover, cooperative learning increases student motivation. Because it enables them to manage their own learning experiences, and it boosts self-esteem that can motivate students to participate (Johnson \& Johnson, 2014; Laal et al., 2012).

The lack of necessary materials in conducting further investigations and exploration in a chemistry classroom viewed as the reason behind the lower insignificant effects of the constructivist methods, inquiry-based, project, and problem-based learning on the attitude outcomes. These learning methods focused on hands-on manipulation, inquiry, investigation, questioning, and primary requires critical and creative thinking and problem-solving skills. Thus, it gives students a negative impact and perceiving it to be difficult, less enjoyable, and inconvenient for the students. The fact that chemistry is one of the subjects that perceived to be difficult because of its being abstract. It justifies the non-significant result of the use of inquiry-based learning towards student motivation, as presented in this meta-analysis. Bayram et al. (2013) emphasized that inquiry-based learning can enhance students' interest and motivation because students are given the freedom to make their own choice. It also provides students the opportunities to deliver self-regulation and allowing them to be involved in projects/activities they are interested in. Hence, this issue puts on the challenge of how the teacher can effectively carry-out the lesson and that how he/she can effectively communicate and execute the instruction to the students. Demirel and Dagyar (2016) concluded in the meta-analysis study conducted that problem-based learning is useful for students gaining a positive attitude and interest toward subjects. Students should have an interest first toward the subject and possess a positive attitude to achieve success. For these affective properties to be evident, teaching methods should be appropriately selected, planned, and executed by the teachers in the teaching-learning process (Demirel \& Dagyar, 2016).

\section{CONCLUSION AND IMPLICATION}

We cast the identified teaching methods in the meta-analysis into treatment categories. We found that cooperative learning, project-based learning, and individualized instruction significantly affect attitude, and only collaborative learning affects motivation. Within the collection of different teaching methods, cooperative learning demonstrated to have the most significant effect on attitude and motivation. We determined that the cooperative learning method is useful for students gaining a positive attitude and motivation toward chemistry as compared with the traditional method. The meta-analytic review concludes that the effectiveness of different innovative instruction on the affective aspect for secondary chemistry is new and less studied in the field. Findings presented that only 14 studies qualified in the meta-analysis. For this reason, the study calls for more empirical research studies to investigate the effects of different teaching methods on student affective properties, attitude, and motivation.

The findings suggest that science educators and researchers need to explore more and further improve existing teaching methods that will significantly tackle and improve the students' attitude and motivation. It is also essential to pursue more meta-analysis studies 
on chemistry education because, in the Philippines, very few meta-analysis studies have been identified. This meta-analysis study is not a mere synthesis of previous knowledge. It is an informative overview of the present state of science education, what has been done and what has to be done in the research area.

\section{REFERENCES}

Adesoji, F. A. (2008). Managing Students' Attitude towards Science through Problem Solving Instructional Strategy, The Anthropologist, 10(1), 21-24.

Ajaja, P. O. \& Eravwoke, O. U. (2010). Effects of Cooperative Learning Strategy on Junior Secondary School Students Achievement in Integrated Science. Electronic Journal of Science Education (Southwestern University), 14(1), 1-18.

Akcay, H., Durmaz, A., Tuysuz, C., \& Feyzioglu, B. (2006). Effects of Computer-Based Learning on Students' Attitudes and Achievements towards Analytical Chemistry. The Turkish Online Journal of Educational Technology, 5(1), 44-48.

Aloraini, S. (2012). The Impact of Using Multimedia on Students' Academic Achievement in the College of Education at King Saud University. Journal of King Saud University-Languages and Translation, 75-82.

Argaw, A. S., Haile, B. B., Ayalew, B. T., \& Kuma, S. G. (2017). The Effect of Problem Based Learning (PBL) Instruction on Students' Motivation and ProblemSolving Skills of Physics. Eurasia Journal of Mathematics Science and Technology Education, 13(3), 857-871.

Ayaz, M. F., \& Sekerci, H. (2015). The Effects of the Constructivist Learning Approach on Student's Academic Achievement: A Meta-Analysis Study. The Turkish Online Journal of Educational Technology, 14(4).

Bayram, Z. B., Oskay, O. O., Erdem, E., Ozgur, S. D., \& Sen, S. (2013). Effect of Inquiry-based Learning Method on Students' Motivation. Procedia Social and Behavioral Sciences, 106, 988-996.

Bloom, B. (1956). Bloom taxonomy of educational objectives: Book 1. New York: Longmans Green.

Bogar, Y., Kalendar, S., \& Sarıkaya, M. (2020). The effects of constructive learning method on students' academic achievement, retention of knowledge, gender and attitudes towards science course in "matter of structure and characteristics" unit. Procedia - Social and Behavioral Sciences, 46, 1766 - 1770.

Caliskan, I. S. (2004). The Effects of Inquiry-based Chemistry Course on Students Understanding of Atom Concept, Learning Approaches, Motivation, Self-efficacy and Epistemology Beliefs. The Middle East Technical University. Retrieved from http://etd.lib.metu.edu.tr/upload/3/12605469/index.pdf. 
Can, B. H. (2012). Students Attitudes toward School Chemistry: The Effect of Interaction between Gender and Grade Level. Asia-Pacific Forum on Science Learning and Teaching, 13(1).

Capar, G. \& Tarim, K. (2015). Efficacy of the Cooperative Learning Method on Mathematics Achievement and Attitude: A Meta-Analysis Research. Educational Science Theory and Practice, 15(2), 553-559.

Cavanaugh, C. S. (2001). The Effectiveness of Interactive Distance Education Technologies in K12 Learning: A Meta-Analysis. International Journal of Educational Telecommunications, 7, 73-88.

Cheng, P. H., Yang, Y. T. C., Chang, S. H. G. \& Kuo, F. R. R. (2016). 5E Mobile Inquiry Learning Approach for Enhancing Learning Motivation and Scientific Inquiry Ability of University Students. IEEE Transactions on Education, 59(2), 147 - 153.

Chiang, C. L. \& Lee, H. (2016). The Effect of Project-Based Learning on Learning Motivation and Problem-Solving Ability of Vocational High School Students. International Journal of Information and Education Technology, 6(9).

Cudney, E. A. \& Ezzell, J.M. (2017). Evaluatıng the Impact of Teaching Methods on Student Motivation. Journal of STEM Education: Innovations and Research, 18(1), 3249.

Demirel, Ö. (1999). Öğretme sanatt. [The art of teaching]. Ankara: Pegema.

Demirel, M. \& Dagyar M. (2016). Effect of Problem-Based Learning on Attitude: A Meta-Analysis Study. Eurasia Journal of Mathematics, Science \& Technology Education, 12(8), 2115-2137.

Dindar, A. C. (2016). Student Motivation in Constructivist Learning Environment. Eurasia Journal of Mathematics, Science \& Technology Education, 12(2), 233-247.

Francis, J. (2017). The Effects of Technology on Student Motivation and Engagement In Classroom-Based Learning. All Theses and Dissertations, 121.

Gabrielle, D. (2003). The Effects of Technology-Mediated Instructional Strategies on Motivation, Performance, and Self-Directed Learning. Proceedings of ED-MEDIA 2003 World Conference on Educational Multimedia, Hypermedia \& Telecommunications, 2568-2575.

Ganyaupfu, E. M. (2013). Teaching Methods and Students' Academic Performance. International Journal of Humanities and Social Science Invention, 2(9), 29-35.

Gill, A. \& Kusum. (2017). Teachıng approaches, methods and strategy. Scholarly Research Journal for Interdisciplinary Studies, 4(36). Doi: 10.21922/srjis.v4i36.10014

Glasman, L., \& Albarracin, D. (2006). Forming Attitudes That Predict Future Behavior: A Meta-Analysis of the Attitude-Behavior Relation. Psychological Bulletin 132(5), 778-822. Doi: 10.1037/0033-2909.132.5.778 
Glass, G. (1976). Primary, Secondary and Meta-analysis of Research. Educational Researcher, 5, 3-8. Retrieved from http://www.jstor.org/pss/1174772.

Gömleksiz, M. N. (2003). Validity and reliability of an attitude scale on affective domain in English course. Firat University Journal of Social Science, (13)1, 215-226. Retrieved from dergipark.ulakbim.gov.tr.

Ganyaupfu, E. M. (2013). Teaching methods and students' academic performance. International Journal of Humanities and Social Science Invention, 2(9), 29-35.

Hancock, D. (2010) Cooperative Learning and Peer Orientation Effects on Motivation and Achievement, The Journal of Educational Research, 97(3), 159-168.

Ilgaz, G. (2006). The attitudes of seventh grade towards the science course and learning strategy use. (Unpublished Master Thesis), Trakya University, Turkey.

Israel, H. \& Ritcher, R. (2011). A Guide to Understanding Meta-Analysis. Journal of Orthopaedic \&Sports Physical Therapy, 41(7), 496-504.

Johnsen, S. (2009). Improving Achievement and Attitude Through Cooperative Learning in Math Class. Action Research Projects. 64. Retrieved from http://digitalcommons.unl.edu/mathmidactionresearch/64.

Johnson, D. W, \& Johnson, R. T. (2014). Cooperative Learning in the 21st Century. Research Gate, 30, 841-851.

Johnson, S. A. \& Cuevas, J. (2016). The Effects of Inquiry Project-Based Learning on Student Reading Motivation and Student Perceptions of Inquiry Learning Processes. Georgia Educational Researcher, 13(1), 50-85.

Kalaian, S. A. \& Kasin, R. M. (2014). A Meta-Analytic Review of Studies of the Effectiveness of Small-Group Learning Methods on Statistics Achievement. Journal of Statistic Education, 22(1), 1-20.

Laal, M., Laal, M. \& Kermanshahi, Z. (2012). 21st Century Learning: Learning in Collaboration. Procedia: Social and Behavioral Science - Elsevier, 47, 1696 - 1701.

Mamolo, L.A. (2019). Analysis of Senior High School Students' Competency in General Mathematics. Universal Journal of Educational Research 7(9), 1938-1944. Doi: 10.13189/ujer.2019.070913

Mamolo, L.A. (2019a). Development of digital interactive math comics (DIMaC) for senior high school students in general mathematics. Cogent Education, 6, 1689639. Retrieved from https://doi.org/10.1080/2331186X.2019.1689639

Mamolo L.A. \& Sugano, S.G.C. (2020). Self-perceived and actual competencies of senior high school students in General Mathematics. Cogent Education, 7(1), 1779505.

Muhammad, Y. (2019). Choosing an appropriate teaching methodology. Retrieved from https://www.researchgate.net/publication 
Nasr, A. \& Soltani, A. R. (2011). Attitude towards Biology and Its Effects on Student's Achievement. International Journal of Biology, 3(4).

Oweis, T. I. (2018). Effects of Using a Blended Learning Method on Students' Achievement and Motivation to Learn English in Jordan: A Pilot Case Study. Educational Research International, 2018.

Papansatasiou, E. \& Zembylas, M. (2002). The Effects of Attitudes on Science Achievement: A Study Conducted Among High School Pupils in Cyprus. International Review of Education, 48(6).

Quinn, P. (2006). Cooperative Learning and Student Motivation. Education and Human Development Master's Theses. Retrieved from http://digitalcommons.brockport.edu/ehd_theses/285.

Rybczynsk, S. M. \& Schussler, E. E. (2012). Effects of Instructional Model on Student Attitude in an Introductory Biology Laboratory. International Journal for the Scholarship of Teaching and Learning, 7(2).

Saeed, S. \& Zyngier, D. (2012). How Motivation Influences Student Engagement: A Qualitative Case Study. Journal of Education and Learning, 1(2).

Schroeder, C. M., Scott, T. P., Tolson, H., \& Huang, T. Y. (2007). A Meta-Analysis of National Research: Effects of Teaching Strategies on Student Achievement in Science in the United States. Journal of Research in Science Teaching, 44(10), 1436-1460.

Schunk, D. H., Meece, J. R. \& Pintrich, P. R. (2008). Motivation in Education: Theory, Research, and Applications, Retrieved https://www.education.com/reference/article/motivation/.

Stirling, D. (2013). Motivation in Education. Retrieved from https://www.researchgate.net/profile/Diana_Stirling/publication/266141351_Motivation _in_Education/links/5426d4540cf26120b7b344e8/Motivation-in-Education.pdf

Sugano, S. G. C., \& Nabua, E. B. (2020). Meta-Analysis on the Effects of Teaching Methods on Academic Performance in Chemistry. International Journal of Instruction, 13(2), 881-894.

Sugano, S. G. C., Nabua, E. B., Barquilla, M. B., Buan, A. T., \& Inutan, E. N. (2019). Meta-analytic review of studies on the effectiveness of chemistry teaching methods on student transformation. Journal of Physics: Conference Series, 1340-012082.

Tohidi, H., Jabbari, M. M. (2012). The effects of motivation in education. Procedia Social and Behavioral Sciences, 31, $820-824$.

Umer, S. \& Siddiqui, J. A. (2013). Improving Trends of Teaching Methods Used in the Concepts of Schools of Karachi: An Evaluative Study. Educational Research International Educational Research International, 2(2). 
Valentine, J. C., Pigott, T. D. \& Rothstein, H. R. (2010). How Many Studies Do You Need? A Primer on Statistical Power for Meta-Analysis. Journal of Educational and Behavioral Statistics, 35(2), 215-247.

Walton, H. J. \& Matthews, M. B. (1989). Essentials of problem-based learning. Medical Education, 23, 542-558. Doi: 10.1111/j.1365-2923.1989.tb01581.x.

Wang, S. K. \& Reeves, T. C. (2006). The effects of a web-based learning environment on student motivation in a high school earth science course. Education Technology Research Development, 55, 169-192.

Wijnia, L., Loyens, S. M. M. \& Derous, E. (2011). Investigating effects of problembased versus lecture-based learning environments on student motivation. Contemporary Educational Psychology, 36(2). 